\title{
Translated Picture Books in Korea from 1969 to 2012
}

\author{
Seonju Ko* \\ Soong Eui Women's College
}

\begin{abstract}
This study aims to explore the characteristics of translated picture books in South Korea and their cultural meanings over a five-decade period. This time can broadly be divided into three periods, being the Settlement Period (pre-1990), the Flourishing Years (1991-2000) and Globalization (post-2001). During the Settlement Period, picture books in South Korea were derived mainly from Japan and America and tended to be informational in nature or based on folk tales. These were translated into Korean to meet the public's curiosity for foreign cultures or for scientific information. The Flourishing Years were characterised by the availability of picture books on a wide variety on themes and forms from all over the world. In this period, the translation of books into Korean focused on a literal rendition of the meanings and sounds of names from the original text. There was also a proliferation of audiotapes, videos and TV programs based on famous picture books. In the current period of Globalization, Korean publishers, who have built confidence through studying foreign picture books over time, have increased efforts to produce their own picture books and export them abroad.
\end{abstract}

Keywords: translation, picture book, South Korea, globalization

\section{Introduction}

South Korean society has been rapidly changing without any comparable examples with other countries (Nahm, 1993; de Mente, 2012). The GDP per capita in 2013 was $\$ 23,837$, which is nearly ten times larger than the corresponding figure of $\$ 250$ per capita in 1969. This remarkable economic development is usually referred to as "the Miracle on the Han River," leading to vast societal, cultural and educational changes. People now witness everyday objects in museums that were once in common use when they were young. For the first time in their lives, most parents must deal with their children's educational materials, the likes of which they never experienced during their school years

* Corresponding Author: Seonju Ko, Assistant Professor, Department of Early Child Education, Soong Eui Women's College, Yejang-dong, Jung-gu, Seoul 100-751, South Korea. E-mail: koseonju@sewc.ac.kr when books, including picture books, were scarce. Nowadays, picture books are ubiquitous, sold on TV home shopping programs and shops in railway stations and shopping malls. Famous picture book characters reappear as dolls or on T-shirts, shoes, tableware, bedding and furniture.

Inquiring into the development of cultural products such as picture books, research methodology can be adopted from cultural studies. Cultural anthropologists and other researchers investigate characteristics of a society or a group by examining an item or items commonly used by members of that society or group. The focus in general is on the producers, the background of its production, responsiveness of consumers, users or viewers, and reasons for its popularity and appearance. Recent studies on children's culture have looked at computer games or Disney characters (Watkins, 2005; Zornado, 2006). 
In 1969 , the first year that publishing records were kept in South Korea, children's books represented $11.5 \%$ of all books being published (KAPC, 2012). From 1980, there was a steady growth in this figure until it reached $23.5 \%$ in 1990 where it has remained relatively constant ever since. It is estimated that around two-thirds of picture books available for purchase in South Korea are translated works (W. K. Baek, personal communication, 2013). According to statistics produced by Kyobo Books, South Korea's largest bookstore chain, there are approximately 5,000 translated picture books currently on sale in the country. In 2012, 10 out of the top 20 best-selling books for young children were translated picture books.

Previous studies on the development of children's picture books focus on picture books of a certain country such as South Korea, England, the United States, Japan, France or Sweden (Hyeon et al., 2008). And research on Korean picture books has dealt only on ones originally written in the Korean language (Cho, 2006; Hyeon \& Kim, 2005). It is high time to draw an overall picture of the development of translated pictures and to reflect its meanings in the Korean cultural context.

Choosing picture books for translation could be seen as part of a process for producing cultural goods and, as such, necessarily reflects the needs and aesthetics of the society at the time. Picture books are also closely related to educational policy, as the primary readers are children and their parents. Along with toys, picture books are regarded as the first material encountered by young children for educational purposes. Most college textbooks for teacher training courses on the subject of early childhood education make their own picture book recommendations and a large portion of these lists consist of translated picture books.

There have been two major changes in the South Korean educational environment since 1990. First, the standardized national university entry exam in South Korea requires candidates to demonstrate their ability to write essays. Parents are now aware of the importance of reading books for composition. This positively affects children's picture book sales. Second, there has been a movement to both establish and publicize children's libraries, which has also had a positive impact on the availability and consumption of picture books.

It has been only relatively recent that scholarly attention has been drawn to the translation of picture books in South Korea. Despite a short history of debates on the matter, there are mainly two conflicting views on the principles of picture book translation. On the one hand, translated picture books should deliver the culture and value of the original books and the original intentions of the authors. In order to do that, the title, names of characters, and even iconotext should be left intact (Kim, 2005; Kwak, 2012). On the other hand, the translation should reflect the needs and the cultural circumstances of the readers (Lee, 2007; Shin, 2005). The speech and sounds of picture book's Korean text are more important, especially for young readers reading books aloud, than a literal translation of the original text.

This study aims to explore the characteristics of translated picture books from 1969 onwards, which was the point of emergence for the children's book publishing industry in South Korea. It is envisaged that reviewing the way picture books have been translated will deepen our understanding about the dynamics of a society and those educational as well as commercial products called books. To reflect the dynamics of the cultural changes that have taken place, three periods are demarcated for this study: the Settlement Period (pre-1990), the Flourishing Years (1991-2000) and Globalization (post-2001).

Research questions in this study are as follows:

1. What are the characteristics of translated picture books across periods in South Korea?

2. What are their cultural meanings? 


\section{Method}

\section{Data Collection}

In order to find the characteristics of translated picture books in each period, the book lists of three major literature institutes were compared. These three institutions were: the National Library for Children and Young Adults in Korea, the Children's Art Book Centre and the Kyobo Books since these had the largest catalogues of children's books. Each list contained book titles, the year of publication, names of authors, translators, publishing company, etc. Common data across these lists were analyzed as validity of the trends for each period. Theme and content, the age of the target reader, translation methodology, the relationship between written and pictorial elements and the size of each book or each series among common data were coded by an early childhood education expert and a librarian.

In order to gather supplementary data on the translations during each period, interviews with four publishers and with two translators were conducted. Questions to the publishers were about the decision making process for choosing which foreign books to publish, the translators, the translation direction, the design, title and size of published books and also each publisher's outlook on the picture book industry. With the translators, the interviews focused on the principles of translation.

Interviews were recorded and transcribed. All comments made by publishers and translators were compared to one another. In general, publishers differed greatly on the decision making process, while translators agreed on the matters of translation principles.

\section{The Settlement Period (Pre 1990)}

Following the end of the Korean War (19501953), picture books in South Korea consisted of illustrated storybooks or collections of poems,

Table 1

Characteristics of Translated Picture Books across Periods

\begin{tabular}{|c|c|c|c|}
\hline Period & Types of Picture Books & Translation & Layout, Size \& Price \\
\hline Pre-1990 & $\begin{array}{l}\text { - Children's classic literature; } \\
\text { focused on storyline } \\
\text { - Encyclopaedia of Natural science } \\
\text { and Information } \\
\text { - Started with Aesop, Anderson, } \\
\text { Grimm \& Folk tales } \\
\text { - Imported mostly from Japan, } \\
\text { America and England }\end{array}$ & $\begin{array}{l}\text { - Revived oral rhythm of } \\
\text { Korean spoken language } \\
\text { - Tended to change titles } \\
\text { names of characters to } \\
\text { Korean ones }\end{array}$ & $\begin{array}{l}\text { - Illustration above, large } \\
\text { letters of written text below } \\
\text { - Started with a large volume, } \\
\text { then downsized to } 32 \text { pages } \\
\text { - Around 4,000 won each }\end{array}$ \\
\hline $1991-2000$ & $\begin{array}{l}\text { - Various themes } \\
\text { - Big books, pop-up books, audio } \\
\text { and video } \\
\text { - Awarded books from all over the } \\
\text { world }\end{array}$ & $\begin{array}{l}\text { - Focused on the exact original } \\
\text { meanings } \\
\text { - Tended to keep original titles } \\
\text { and names } \\
\text { - Displayed the translator's } \\
\text { name on the front cover }\end{array}$ & $\begin{array}{l}\text { - Various sizes, but volumes } \\
\text { were mostly } 32 \text { pages } \\
\text { - Double page illustration } \\
\text { appear } \\
\text { - Around 8,000 won each }\end{array}$ \\
\hline Post-2001 & $\begin{array}{l}\text { - Picture books without words } \\
\text { - Special purposes such as special } \\
\text { needs, multicultural education, } \\
\text { and nature preservation. } \\
\text { - Collection of works of individual } \\
\text { illustrators } \\
\text { - Exporting Korean picture book to } \\
\text { France, Japan, America, etc. }\end{array}$ & $\begin{array}{l}\text { - Translating Korean picture } \\
\text { books to Japanese, English, } \\
\text { French, etc. }\end{array}$ & $\begin{array}{l}\text { - Around } 20 \times 25 \mathrm{~cm} \\
\text { - Mostly hard cover } \\
\text { - Around } 10,000 \text { won each }\end{array}$ \\
\hline
\end{tabular}


which were largely translated or abstracted from Western cartoons or Japanese magazines. The foreign source material was not subject to copyright protection in South Korea and, as the content had been pirated, the names of the original authors or illustrators were not published with the Korean translations (Ryu, 1985).

The introduction of book series was of most importance in the translation of books as well as book markets. The most common form for picture books until the early 1970 s was a pocket edition with only a few pictures. For the first time, a collection of stories and biographies was published by the Art and Culture Company in 1972. The collection consisted of 10 books in total and included The Arabian Nights, Aesop's Fables, Greek Myths, Macbeth and the biographies of Thomas Edison and Mahatma Gandhi. Each volume was around 220 pages, but only four pages contained illustrations, with the exception of Aesop's Fables, which featured many more pictures and large illustrated Korean script at the beginning of each paragraph. The dark blue hard covers of the volumes rendered the collection with an overall serious or solemn impression. The books were $15.3 \times 20.7 \mathrm{~cm}$ and sold for a price of 700 won. A second collection of 20 books came out with black and white pictures in 1983 and included Robinson Crusoe, Cinderella, Little Mermaid, Gulliver's Travels, and Alice in Wonderland. The content of these volumes is broadly similar to currently published versions of these children's classics and, as such, later versions must have been directly or indirectly based on the books in these collections. The collections featured the names of the authors, such as Oscar Wilde or Lewis Carroll, but not of the illustrators or translators.

The appearance of these book series signals the formulation of a middle class in South Korean society who wished to collect books. Popular books for the public began to appear in the book market, too. Many versions of Aesop's Fables were translated with variations between the different versions. For example, one particular version contained 314 fables with vertical script and a few pictures, which was written by Dong-Wha Cho and published by
Samter. The author, Cho, made clear that reference was made to several earlier editions, such as versions published in France in 1927, by Penguin in 1954, in Japan in 1941 and in South Korea in 1956.

Picture books in color appeared in the mid1970s in South Korea for the first time. The World Collection of Children's Books consisted of 20 books and included The Happy Prince, Aesop's Fables, Hans Christian Andersen's Fairy Tales, Mother Goose Tales, Perrault's Fairy Tales and Grimms' Fairy Tales. Each double page spread contained at least one picture and large sized text. Two sizes of books were published: $15 \times 22 \mathrm{~cm}$ or $19.2 \times 26.4 \mathrm{~cm}$. The written text was identical in both versions.

The publication of color books represented a technical advance in book publishing as evidenced by its high expense. Observation on Nature (1978) and the New Children's Observation on Nature (1983) published by Korean Froebel were each 30 pages long and therefore much lighter than the earlier collections of children's picture books. These books were more factual in nature, featuring information on animals, insects, flowers or fruits. The Japanese Froebel's exclusive copyright is marked on the back cover.

From 1980, the number of foreign picture books being translated and published increased with the general rise in the number of children's books produced and available in South Korea. Later collections such as Froebel Picture Books (1981), World Literature for Boys and Girls (1986) by Children's Literature Co., World Classics of All Colours (1981) by Kyungmee Co. and the World's Most Interesting Folk Tales (1991) by Yeowon featured the names of Korean writers, but not of the illustrators.

The target age of children's book became younger. The first baby book series in South Korea was translated and published in 1979 by Samter Co. Books for the Growth of Imagination of Babies consisted of five books, including The Adventure of Red Balloon, The Tree, The Squirrel and the Birds, Blue and Yellow, and Don't Pet the Animals. The first three books have no written text. The translator on the 
remaining two books is listed as the publishing company, rather than an individual translator. The price of these books was 1,200 won each.

Soft-bound picture books started to be published in 1979. Well-known authors, such as Leo Lionni, Shel Silverstein or Trina Paulus, were introduced in the Bundo series. Translated books included Fredrick and the Biggest House in the World by Lionni, The Giving Tree and Where Is the Other Half of Me? by Silverstein, and Hope for the Flower by Paulus. The first volumes of Fredrick were published in 1980 and there were subsequently 11 more printings until 1999. The first version had 35 pages with four pages of English text at the back. Its size was $17.7 \times 22 \mathrm{~cm}$ and the price, 4,000 won. The name of the translator, Young-Hee Lee, appears on the title page, but not on the front cover. Neither the author nor the translator had their own introduction. The translated text had fixed measures of syllables which is very similar to that of traditional Korean poems. When the text is read aloud, it sounds beautiful.

There were two remarkable series of translated picture books with solid storylines accompanying beautiful pictures in the late 1980s. One was The World Young Children's Picture Books (1988), which introduced translations of well-known Japanese picture books, such as The Red Apple and I've Grown Up Now by Nagana Hiroda; Whose Baby is it? and Whose Strange Foot Prints Are These? by Yavwoochi Masauki; and Hide and Seek in the Forest by Sueyosi and Hyayashi Akiko. The other was 140 books in the Great Birth series (1989) by Bolim Company. The series introduced world famous picture books and illustrators, for example, Circus by Brian Wildsmith, Santa by Raymond Briggs, The Mixed-Up Chameleon by Eric Carle, The Giant Apple by Dada Hiroshi, and The Gift through the Window by Gomi Taro. The front cover page of The Mixed-Up Chameleon stated that that the book was intended for oral presentation. The size of these books was $26.4 \times 21 \mathrm{~cm}$. The translation was characterised by short sentences and the books had fewer pages than the original source texts. The Korean text featured cannot be said to be an accurate translation of the originals as they are briefer, but feature the important points of the storyline. The Korean text sounds natural in speech when read aloud.

In the late 1980s, encyclopaedias with color photos and collections of natural sciences books were in mass production. Published in 1987, the Dong-A Color Illustrated Guide of Science Studies was of Japanese origin and included volumes on Vegetables and Fruits, the Observation of Stars, the Observation of the Moon, the Observation of Wild Birds etc. In 1989, the Britannica Discovery Library series was published in South Korea. Each volume had 45 pages with titles such as What is a World?, What is Time?, What is an Animal?, What is Sound? and What are We?. The number of similar collections published, which all featured multiple volumes (up to 70) and were large in terms of physical dimension and number of pages, is evidence of their popularity. Other titles include The Young Children's Encyclopaedia (1987) by the Korean Britannica, Our Body (1987) by Education Culture Co., Experiments, Discovery, Science Play (1988) by Gold Star Publishing, and Color Nature and Science (1989) by Enlightenment Co. The names of the supervising editor or author were featured in these books. This trend of extravagant and expensive collections of books was not limited to reference or science books, but continued with picture storybooks and children's literature. Their popularity reflected the growing size and wealth of the middle class population in South Korea after successive years of economic development following the war and the importance placed on their children's education.

It was only in 1987 , towards the end of the Settlement Period, that the South Korean government signed the International Regulation of Copyrights. Prior to this, the same foreign books were often translated and published by several different publishers unregulated, both under the same or a different title. Examples of titles under which this occurred included The Giving Tree, Hope For the Flowers and Pezzettino. The prevailing themes in these books include freedom, self-identity and a nationalist 
spirit, and contributed to the liberation of the minds of Korean people at the time, who desired democracy following a period of dictatorship. In some versions of these books, the translated text was beautifully rendered, reviving the rhythm of the Korean oral language. The titles of the books and the names of the characters were changed to sound "Korean." At this point, the status of the translator was elevated from the nameless to being akin to a second writer and cultural transmitter.

\section{The Flourishing Years of Picture Books (1991-2000)}

In the early 1990s, two government policies favored the publishing industry in South Korea. Book tokens were introduced in April 1994, which could be used to purchase books. By the end of the year, 400,000 tokens had been sold, each with a value of 5,000 won. One million tokens were sold by September the following year. Book tokens were popular gifts for birthdays, graduations and holidays and had a positive effect on the book market and publishing industry at the time. Furthermore, the year 1993 was announced as The Year of the Book. The nation was encouraged to read through a variety of campaigns promoted during the year.

There are a number of picture book series that were first published during the 1990s and are still published today, having continued to be very popular in South Korea. These include the Never Land World Classics Picture Books by Sigong Co., Bir's Picture Story Book by Bir Co., Montessori Picture Books by the Korean Montessori, World Picture Books by Woongjin Think Big. These companies produce around 10 picture books per year. Jikyung Co., Sakyejul, Marubol, Jungang Publishing Co., Hollym, Crayon House, Five Wagon, Baby World and Green Frog are smaller publishers, which have a reputation for producing quality translated picture books. Books published by the above companies disclose details of the original texts and copyrights. Most of the books published are approximately 36 pages long and priced between 4,500 and 8,000 won. The name of translator is printed on the book in this period.

The publication of the Never Land World Classics Picture Book series began in 1993 and more than 200 books have been published to date, including Millions of Cats (Wanda Gag's original version published in 1928 and translated by Mu-Hwan Kang in 1994); Choo Choo (Virginia Lee Burton's original version published in 1937, translated by Mi-Yeon Hong in 1994); Caps for Sale (Esphyr Slobodkina's original version published in 1940, translated by Ju-Hyang Park in 1999); Good Night Moon (original version written by Margaret Wise Brown and illustrated by Clement Hurd in 1937, translated by Yeon-Sun Lee in 1996); Tomi Ungerer's Crictor (originally published in 1958, translated by Mi-Ran Jang in 1994) and Die Drei Rauber (originally published in 1961, translated by Hee-Jeon Yang in 1995); Mr. Gumpy's Outing (John Burningham's original version published in 1970, translated by Ju-Ryeong Lee in 1996); and Mauris Sendak's Where Are Wild Things Are (originally published in 1963, translated in 1997 by Moo-Hong Kang) and In the Night Kitchen (originally published 1970 and translated in 1994 by Moo-Hong Kang). All these books played a part in opening the eyes of young Korean readers.

Sakyejul was the first major publisher of French and German picture books in South Korea. The publisher's all-time bestseller is Vom kleinen maulwurf, der wissen wollte, wer ihm auf korfu by Wolf Erlburch (1993). Marubol's Good Picture Books favor Leo Lionni and the series has published more than 10 of his works, starting with An Extraordinary Egg and Swimmy, which were both translated by Myeong-Hee Lee in 1997.

Bir's Picture Story Book series started in 1995 with books by Raymond Briggs, John Burningham and William Steig and consists of more than 160 translated books today. During the first few years, the series published books by Brian Wildsmith and Gomi Taro, who Korean readers were familiar with because of the Great Birth series in earlier years. In 1995, three of 
Briggs' books were translated-The Bear and Father Christmas by Sang-Hee Park and Father Christmas Goes on Holiday by Jeong-Ha Kim. In the same year, Eun-Soo Cho translated three of Steig's works-Spinky Sulks, The Amazing Bone and Doctor Desoto. The following year, three of Wildsmith's books were translated: The Miller, the Boy and the Donkey (Eun-Soo Cho), Goat's Trail (Jeong-Ha Kim) and Give A Dog A Bone (Sook-Hee Park).

However, it was Burningham, 10 of whose books were translated and published, who took the most prominent position in the series, including Grandpa, John Patrick Norman McHenessy and Oi! Get Off Our Train (all translated by Sang-Hee Park between 1995 and 1996); Borka (translated by Jin-Soo Lee in 1996); and Courtney (translated by Seung-Hee Ko in 1996).

The Korean Froebel series has a long-running bestseller, Guess How Much I Love You by McBratney, which was illustrated by Anita Jeram and translated in 1996 by Seo-Jeong Kim. The book depicts a loving relationship between a father and a daughter.

During the Flourishing Years, Korean readers were exposed to a variety of acclaimed picture books and were therefore able to develop their own tastes and notions as to what constituted a "good" picture book. Books introduced during this time, which had received the Caldecott Award, included Burton's Little House translated by Yeon-Mi Hong in 1993 and Ezra Jack Keats' Snowy Day by So-Hee Kim in 1995; Steig's Sylvester and the Magic Pebble translated by Sang-Kyeong Lee in 1994, and Steig's The Amazing Bone, Lionni's Swimmy, Simms Taback's Joseph Had a Little Overcoat by Jeong-Hee Kim in 2000. Newberry Award books (Doctor De Soto, see above) and Kate Greenaway Award books (Pat Hutchins' The Wind Blew translated by Hyeon-Cheol Park in 1997 and Burningham's Borka and Mr. Gumpy's Outing) were characterized by the wellrecognized gold or silver award seals on the front covers.

The 1990s represented an era characterized by the decline of ideology resulting from the collapse of the Soviet Union and the unification of Germany. In 1991, both South and North Koreas joined the United Nations. In December of the same year, the two nations signed an agreement for communication and exchange. During this time, sales of books on the theme of ideology conflict declined and publishers of these books restructured their businesses to focus on children's books instead.

There was a noticeable shift in the spirit of the time from prohibition and admonishment to tolerance for differences and social awareness. Contents of children's stories became broader, featuring themes such as a power shift from adults to children, running away from home, health and the environment.

The variation in the types and styles of picture books published during this time is also recognizable. Large books, books featuring multiple pictures per page in the style of cartoons, board books, pop-up books, and audiotapes in the early 1990s to video tapes and TV animation in later years were based on the characters and storylines of famous picture books.

The IMF economic crisis of the late 1990s had a disastrous effect on the book industry with many publishers and book stores being forced into insolvency. The number of books produced in 1999 reduced by $41 \%$ when compared to the previous year.

Spellings for foreign names or places when translated into Korean had not yet been standardized and the official governmentapproved revised Romanization of Korean language law was only implemented in July 2000. Shortcomings of translations can be commonly witnessed in the titles or contents of books translated and published prior to this time. For example, the published title for Sylvester and the Magic Pebble in South Korea was Sylvester the Donkey and the Magic Pebble. This type of re-titling was born out of ignorance in respect of the role of title and as a way of gatekeeping the book's contents (Nikolajeva \& Scott, 2001). Furthermore, careless page formats and layouts caused a distortion between the written text and the related image regardless of the writers' original intentions. 


\section{The Globalization of Picture Books (Post 2001)}

A huge demographic change that has taken place in South Korea over the past 15 years is the rapid growth in the number of immigrants. People who have a national background that is not Korean are currently $2.8 \%$ of the whole population of South Korea, compared to less than $1 \%$ in 1997 (MOPAS, 2012; Lee, Choi, \& Park, 2009). The number of children under six years of age living with a parent whose racial/ethnic background is not Korean is now estimated at 104,694 , which is $62.1 \%$ of the total number of children who have a parent with a non-Korean background. This suggests a demand in the market for books geared towards a multicultural readership.

The purpose of multicultural education can be seen to be two-fold (Ko \& Lee, 2013). The first is to create an understanding of a multicultural society for everybody, which is approached by promoting the dynamics of a mixed culture. Cultural diversity around the globe is shown in World Folk Tales published by Bir Company. The other is for the education of children from multicultural backgrounds. Academics in the area of early childhood education and social services explore ways to promote an awareness of the Korean language to children who are deprived of mother-tongue input and who therefore face a greater challenge in this respect. South Korea is only at the starting point of publishing picture books especially for children with multicultural backgrounds.

Many of the picture books available featuring themes on human rights and children's rights are Japanese translations, such as Huse Yasko's It's Nice to be Different!, which was translated by Hyang-Geum Kim in 2007. The original version of the book published in Japan featured text that was written line by line in both Japanese and in English, intending to show the differences between the two languages. The Japanese text was then translated into Korean for publishing in South Korea. This could be promoted as a good tool for studying English, but the book could also be used for the purposes of multicultural education. A further example is It Is Only a Small Difference, written by Iwakawa Naoki, illustrated by Kihara Chiharu and translated by Sun-Sook Kim in 2006.

Since 2000, nearly every Caldecott and Kate Greenaway awarded book has been translated immediately or within a few years of receiving the award. From the interviews conducted, publishers cited that the distinct personal character of the writer, degree of completion of work and themes and messages from the book's contents were their top three criteria in their selection for translation. Negative factors were content which was too out of touch with Korean emotions or works which were difficult to understand.

Four picture books without text by David Wiesner (Tuesday and Flotsam, which were awarded the Caldecott medal, and Sector 7 and Free Fall, which received the Caldecott Honor), have been published in South Korea since 2001. Though the educational value and use of picture books without text in educational settings was neglected when first published, they received growing acknowledgement following a focus on the importance of nurturing creativity in the 2000s. The storyline of the book can only be deduced by a careful examination of the pictures therein. Reading not what is written but what the reader makes sense of from the pictures requires that the reader exercise their imagination and creativity. Readers of these books are encouraged to replace the traditional voice of the writer with their own. The production and popularity of these books highlights the importance of speech, rather than script, in postmodern culture. It also reflects the paradigm shift in education from learning basic skills and knowledge through lecture to reliance on the student's own discovery process. The importance of visual skills gained through reading picture books has been emphasized (Arizpe \& Styles, 2003; Gerrard, 2008; Watson \& Styles, 1996). Furthermore, positive effects of reading picture books without text on children's imagination and emotional development are well documented (Kim, 2013; Jung, 2013). These are the reasons why picture books with no written 
text are welcome in an era that values one's personal reading experience and individuality.

In recent years, book reviews, guides and activities are featured toward the back of picture books and are usually produced by the translator of the book. As a result of the establishment of picture books as a key educational tool, reading suggestions and follow-up activities like talking, painting and dancing are widely encouraged.

A further characteristic of the Globalization era is the proliferation of parody. Mini Grey's The Adventures of the Dish and the Spoon parodies the characters from the nursery rhyme, Hey Diddle Diddle the Cat and the Fiddle. The book received the Kate Greenaway Award in 2007 and was translated by Hyang-Geum Kim the following year. Other examples of picture books based on parody are Barbette Cole's Princess Smarty Pants (translated by Eun-Jeong Noh in 2005), Lauren Child's Who's Afraid of the Big Bad Book (by Ji-Young Lee in 2008), Wiesner's The Three Pigs (by Ok-Yong Lee in 2002) and Jon Scieszka's The True Story of the Three Little Pigs (by Eui-Bang Hwang in 2008).

The notion of human-constructed fiction is emphasized by the structure of the books. For example, the story starts on the front cover or on the title page, or the characters appear to leave one story for another. These features afford the readers with gaps where they are able to create their own story line. Parody breaks the traditional way stories are told and gives rise to continuous experiments with classics. For example, Anthony Browne took motifs from several fairy tales and combined these in Into the Forest (translated by Eun-Mi Hur in 2004).

Parody is also easily seen in pictures and Anthony Browne's works demonstrate this as well. Voices in the Park, for example, is a postmodern construction of four characters' different interpretations of the events encountered during an afternoon walk. A picture of a female gorilla is being sold on the street as a parody of the Mona Lisa. The books, Zoo and Gorilla, also depict icons from the 20th century, such as Superman, Marilyn Monroe or Charlie Chaplin as gorillas.

Globalization for the South Korean book industry started with the appearance of Korean picture books in the international book market from the late 1990s and with growing prominence in the 2000s. In 2002, Yellow Umbrella (2001), illustrated by Jae-Soo Liu, was selected as the New York Times Picture Book of the Year. In 2004, two Korean books were awarded Ragazzi fiction and non-fiction prizes for the first time at the Bologna International Children's Book Fair. The titles were The Subway Train is Coming (2003) by Dong-Jun Shin and Red-Bean Porridge Granny and the Tiger (2005), written by Ho-Sang Cho and illustrated by Mi-Sook Yoon. Since this time, Korean picture books have annually received various international awards.

At least 27 countries now import children's books, including picture books, from South Korea according to statistics published in 2008. Following the translation in 1990 of The Myth of Mt. Baekdu by Jae-Su Liu (1988) into Japanese, more than 40 additional picture books have been exported to Japan. Flamarion, a French publisher, has a branch dealing exclusively with Korean books. South Korea also hosted the 2005 Frankfurt Book Fair and 2009 Bologna Children's Book Fair, where 35 Korean publishers attended and generated business with a net worth of US \$7 million from 612 contracts. Chief components of success were the illustrators who are skilled at rendering stories with pictures. Illustrators such as Byeong-Ho Han, Yoon-Deok Kwan, Ho-Baek Lee, HyeonJu Bae, Uk-Bae Lee, Hyeon-Ju Chae and DongJun Shin were trained at domestic art colleges in South Korea. Later experiences at international exhibitions and books fairs and exposure to foreign picture books have helped to generate their varied creative styles. Recently, graduates from the Korean School of Illustration who had attended classes organized by groups of publishers and advertised their work online, received international awards and obtained contracts from foreign publishers.

The process of how picture books are produced in South Korea has been evolving. Korean writers have been working with foreign illustrators. Publishers such as Nonjang, Sakejul, 
Bolim, Easy Books, Yewon, and Changjak \& Bipyeong invite foreign illustrators to plan, design and edit with them. Iwona Chmielewska has illustrated more than 10 books while working with Korean writers like Young-Kwun Kwag and Ji-Won Lee. Her work on The House of the Mind, written by Hee-Kyung, Kim won the Ragazzi Non-fiction Award at the 2010 Bologna International Book Fair. A marked level of success has been established with this type of joint effort production.

According to the Korean Association of Publishing and Culture, the number of new children's books newly published in 2010 was 7,352 , excluding cartoons and study aids. Of these, 2,317 related to translated books, making up $29.1 \%$ of the total. The nations exporting children's books to South Korea were USA (642), Japan (374), France (320) and UK (291) from highest to lowest rank.

With the growth of the picture book market over the years, competition over the licenses of publications has been fierce. Agencies auction for licences, driving their prices up. Even though individual companies such as Random House have agreed to direct contracts with foreign companies in recent years, most publishers rely on agencies, which deal with royalty matters and the price of the license, and are given the responsibility for making contracts with companies both domestically and overseas. The agencies are responsible for producing sales reports and monitoring royalties, usually for five years following the contract date. The big four Korean agencies-KCC, Shinwon, Eric Yang and In Prima Korea-control 80-90\% of the entire market. Despite this domination, there are hundreds of other agencies also in the business.

As a result of the high prices of licenses, some publishing companies prefer works of Korean writers to translations of foreign picture books. In 2000, big publishers such as Bir Co., Kookminseokwan, Sikongsa, Woongjin Think Big and Hansol each produced around 30 picture books. Thirty to forty percent of the books published were translated works. Smaller publishers, such as Marubol and Daniel Stone
Kid, produce around 10 picture books a year. Translated books are up to $90 \%$ of the products in some cases.

\section{Discussions}

Questions regarding the cultural context in which children are raised in and how this affects a child's development have been major debates in the academic field of early childhood education. This study examined what changes were observed in children's picture books, more specifically in their translation. It was found in this study that the development of children's picture books reflected changes in South Korean society, which has relentlessly moved forward and become multicultural and globalized.

It was found that the emergence of encyclopaedias of natural science as an important type of picture book translated in the pre-1990 period reflected the fact that parents associated their lack of scientific knowledge as the main source of their poor living conditions. They valued books containing information about nature and science. Picture books of free-spirited stories gained much publicity as well. These emotionally supported the politically suppressed minds of parents who yearned for true democracy during a time of political turmoil and reflect the desire for the next generation to realize this. With those picture books, they guided the spirit and mindset of their offspring.

As the country's economy improved, parents bought book series for children. The volumes in these series grew larger and more luxurious. Little attention was paid to the precision of translation in the original texts. The society focused on growth, not authorship intents.

In the flourishing years of the 1990s, publishers became savvy in learning what made quality picture books, and began translating and publishing award-winning books and books by world-famous authors. Various themes and forms of picture books were available for readers since the end of the Cold War and the start of talks between South and North Korea allowed a broad spectrum of topics and tolerance over 
differences. Sound and moving pictures were added to the reading experience as audiotapes and video based on famous picture books became available.

In the globalization period of the post-2000 era, South Korea increased in its number of immigrants and became multicultural. The world book market started to recognize the creativity and authenticity of Korean picture books. A real sense of a two-way communication with the world begins to build in Korean minds. Picture books about traditions of other culture were welcomed, as were books about Korean tradition abroad.

One of the characteristics of the Korean domestic picture book market is the existence of many books that have been steady sellers since being published. Rainbow Fish, which was introduced to the market in 1994, and An Apple Drops! in 1989 were both still featured on the 2010 Kyobo Books bestseller list for young children. Picture books are usually published as a series and are also sold in single unit copies as well as part(s) of the total series. Those who start with one copy often end up with the entire collection, which results in the steady sale of picture books. Korean parents who came of age before this last period have become active buyers of what they never experienced as a child. They believe that what their child reads affects the person he or she becomes.

The compositions of popular picture book series have changed over time. In the 1980s, the works of several world-famous illustrators such as Leo Lionni, Eric Carle, Shel Silverstein and John Burningham were combined to make a series. During this time, Korean readers became familiar with the basic concepts and knowledge of the characteristics of good quality picture books. In the post-1990 period, a series of picture books often focused on the works of one particular artist like Dick Bruner, Anna Clara Tidholm, Bruce Degan, Walter Wick or Mo Willems. Authenticity or a marked individuality seemed to be a selling point.

Future goals for publishers of children's picture books in South Korea should take into consideration the following observations. First, cultural crossover trends should aid the successful exportation of Korean books overseas. Investment in illustrators helps to establish a brand, under which exported books could be marketed. Second, picture book contents should appeal universally, rather than being restricted to Korean emotions. Third, basic records should be maintained. Unfortunately, there still are no statistics on the number of picture books published in South Korea each year and this is merely derived from the number of children's books published overall. The role of agencies is also important in obtaining high prices for licenses of Korean picture books in the international markets. For this, good business strategies are needed.

Acknowledgements: This study was supported by the 2013 Soong Eui Women's College Research Fund.

\section{References}

Arizpe, E. \& Styles, M. (2003). Children reading pictures: Interpreting visual texts. New York: Routledge/Falmer.

Cho, E. S. (2006). The history of development for Korean picture books. Journal of Children's Literature and Education, 7(2), 113-151.

de Mente, B. L. (2012). The Korean mind: Understanding contemporary Korean culture. Hong Kong: Turtle.

Gerrard, E. E. (2008). Picturebooks as visual literacy: The influence of illustrations on second-graders' comprehension of narrative text. Journal of Psychology, 45, 255-287.

Hyeon, E. J. \& Kim, S. H. (2005). Understanding picture books. Seoul: Sakejul.

Hyeon, E. J., Kim, S. H., Ko, S. J., Oh, Y. J., Lee, S. Y., Cho, E. S., Masaki, G., \& Kim, M. J. (2008). The history of picture books. Seoul: Hakjisa.

Jung, A. R. (2013). The effects of extension activities using wordless picture books on children's emotional intelligence (Master's thesis). Graduate School of National University 
of Education. South Korea.

KAPC (2013). The Korean year book of publication. Paju: The Korean Associates of Publication and Culture.

Kim, D. H. (2005). Translation of graphic device in where wild things are. Language Science, 12(3), 25-39. Seoul: Korea.

Kim, J. E. (2013). A study on effects of wordless picture books for children's imagination (Master's thesis). Sookmyung Women's University. South Korea.

Ko, S., \& Lee, S. E. (2013). The effects of picture-book shared reading training of immigrant mothers of young children: An exploratory study. Asia-Pacific Journal of Research in Early Childhood Education, 7(2), 29-46.

Kwak, S. H. (2012) Understanding translation: English to Korean. Seoul: Korea Culture Co.

Lee, I. A. (2007). Translation strategy for speakability of picture books based on skopos theory (Master thesis). Pusan University of Foreign Studies, South Korea.

Lee, S. S., Choi, H. J., \& Park, H. J. (2009). Impact of multi-cultural family on quantity and quality of population in Korea. Korea Institute for Health and Social Archives.

Ministry of Public Administration and Security (2012). www.mopas.go.kr
Nahm, A. C. (1993). Introduction to Korean history and culture. Seoul: Hollym.

Nikolajeva, M., \& Scott, C. (2001). How picturebooks work (2nd ed). New York. NY: Routledge.

Ryu, J. S. (1985). Circumstance and tasks of children's book illustration in Korea. Design, $5,38-44$.

Shin, J. S. (2005). The shift of sentence types in the translation of picture. Fairy Tales and Translation, 10, 75-91. Seoul: Korea.

Watkins, T. (2005). Space, history and culture: The setting of children's literature. In P. Hunt (Ed.), Understanding children's literature $\left(2^{\text {nd }}\right.$ ed.). New York: Routledge.

Watson, V. \& Styles, M. (1996). Talking pictures: Pictorial texts and young readers. London: Hodder \& Stoughton.

Zornado, J. L. (2006). Investing the child: Culture, ideology, and the story of childhood. New York: Garland Publishing.

Received February 2, 2014

Revision Received February 19, 2014 Accepted February 20, 2014 